\title{
Ciborgues e Black Mirror na cultura contemporânea
}

\author{
Cyborgs and Black Mirror in the contemporary culture \\ Cyborgs y Black Mirror en la cultura contemporánea
}

\begin{abstract}
Alexandre Manduca - Fatec Ipiranga | São Paulo | SP | Brasil | E-mail: alexmanduca@yahoo.com.br | Orcid: 0000-0001-9473-3878
\end{abstract}

Wilton Garcia - Fatec Itaquaquecetuba | Itaquaquecetuba | SP | Brasil | E-mail: wgarcia@gmail.com Orcid: 0000-0001-9598-2323

Resumo: Este texto problematiza a (re)dimensão do ciborgue na cultura contemporânea, ao utilizar como exemplificação a série Black Mirror, em especial o episódio Toda a sua história (2011), direção de Brian Welsh. O percurso metodológico organiza-se a partir do formato ensaio, ao (re)considerar a dinâmica de observação, descrição e discussão. Nesse sentido, os estudos contemporâneos entrelaçam-se em atualização e/ou inovação. Por certo, a relevância do estudo aponta para a produção do conhecimento, da subjetividade e da informação no campo contemporâneo da comunicação e cultural, cujos resultados obtidos elencam a produção de efeito.

Palavras-chave: Ciborgue. Black Mirror. Cultura contemporânea.

Abstract: This text problematizes the (re)dimension of cyborg in contemporary culture, using as an example the Black Mirror series, especially the episode All its history (2011), by Brian Welsh. The methodological course is organized from the essay format, by (re)considering the dynamics of observation, description and discussion. In this sense, contemporary studies intertwine into update and/or innovation. Certainly, the relevance of the study points to the production of knowledge, subjectivity and information in the contemporary field of communication and culture, which results list the production of effect beams.

Keywords: Cyborg. Black Mirror. Contemporary culture.

Resumen: Este texto problematiza la (re)dimensión del cyborg en la cultura contemporánea, utilizando la serie Black Mirror como ejemplo, especialmente el episodio Toda su historia (2011), dirigido por Brian Welsh. La ruta metodológica se organiza en función del formato del ensayo, cuando (re) considera la dinámica de observación, descripción y discusión. En este sentido, los estudios contemporáneos están entrelazados en la actualización y / o innovación. Ciertamente, la relevancia del estudio apunta a la producción de conocimiento, subjetividad e información en el campo contemporáneo de la comunicación y la cultura, cuyos resultados enumeran la producción del efecto.

Palabras clave: Cyborg. Black Mirror. Cultura contemporánea.

- Recebido em: 28 out. 2019 • Aprovado em: 05 dez. 2019 e-ISSN: 2177-5788

DOI: https://doi.org/10.22484/2177-5788.2020v46n1p39-57

Copyright @ 2020. Conteúdo de acesso aberto, distribuído sob os termos da Licença Internacional da Creative Commons-CC BY-NC-SA - Atribuição Não Comercial - Permite distribuição e reprodução, desde que atribuam os devidos créditos à publicação, ao autor(es) e que licenciem as novas criações sob termos idênticos. 
O ser humano é antes de tudo o ser encarnado,

e o complexo desse ser encarnado significa que a consciência humana se desdobra de maneiras muito diferente da inteligência incorporada nas máquinas cibernéticas ${ }^{1}$.

(HAYLES, 1999, 283-284)

\section{Introdução}

A epígrafe de Katherine Hayles (1999) coloca em questão a condição humana para além da virtualização do corpo na cibernética e a entrada expansiva do código binário (zero e um) como unidade mínima de representação na cultura digital. Nessa atmosfera, o ser humano ambientase nas predisposições entre sujeito (úmido) e máquina (seco), cuja distância (inter)media o esforço de se constituir para além do convencional, com próteses artificiais que auxiliam no desenvolvimento performativo da vida social. No fluxo, um jogo relacional opera entre cognição, consciência, inteligência.

Disso, a inquietação crítico-reflexiva provoca, inevitavelmente, uma discussão em forma de pergunta: como pensar a respeito da (re)dimensão do ciborgue no âmbito dos produtos culturais contemporâneos?

O presente texto (re)dimensiona o ciborgue na cultura digital, ao utilizar como exemplificação a série Black Mirror, em especial o episódio Toda a sua história (2011), direção de Brian Welsh. A imprevisibilidade de temas complexos e paradoxais toma conta da cena na disposição de informações contemporâneas cujo desafio experimenta avanços digitais.

O percurso metodológico organiza-se a partir do formato ensaio, ao (re)considerar a dinâmica de observação, descrição e discussão. Nesse sentido, os estudos contemporâneos entrelaçam-se atualização e/ou inovação. Tais estudos estimulam uma desobediência epistemológica, ao aproximar diversos/as autores/as dos estudos culturais e das tecnologias

\footnotetext{
${ }^{1}$ Human being is first of all embodied being, and the complex of this embodied being mean that human awareness unfolds in ways very different from those of intelligence embodied in cybernetic machines.
} 
emergentes. Por certo, a relevância desse estudo aponta para a produção do conhecimento, da subjetividade e da informação no campo contemporâneo da comunicação e cultural, cujos resultados obtidos elencam a produção de efeito.

Com a inscrição dessas notas preliminares, o referido texto está dividido em três tópicos: A (re)dimensão ciborgue; A ficção científica; e 0 grão em Black Mirror. O primeiro tópico localiza a noção de ciborgue e seus fundamentos; já o segundo acena para a dinâmica aplicada pela ficção científica e sua relevância. Por último, o terceiro exemplifica o objeto em debate. Por conseguinte, são tópicos consistentes que se complementam, de acordo com a demanda exigida.

\section{A (re)dimensão ciborgue}

Em 1985, a feminista Donna Haraway apresentou seu livro Manifesto ciborgue (2013), no qual decreta que qualquer um de nós, de alguma maneira, somos ciborgues, uma vez que utilizamos artefatos externos ao corpo humano como intercâmbio cultural da expressão humana. Ou seja, tanto usamos dispositivos tecnológicos, de forma frenética (como: óculos, aparelhos auditivos, marca-passos, pernas e braços mecânicos), quanto por outros dispositivos que incorporamos ao corpo (implantes eletrônicos, biochips etc.), além de relógio, bengala etc.

Conforme Santaella (2003), também conhecido como biocibernético, o ciborgue (cyborg) é um ser híbrido revigorado que estabelece um novo estatuto do corpo com inúmeras possibilidades eloquentes, aliado à engenharia genética e à vida artificial. O termo ciborgue, esclarece a autora, foi usado pela primeira vez, em 1960, no artigo Cyborgs and space, do engenheiro Manfred Clynes e do psiquiatra Nathan Kline, após uma experiência com alteração fisiológica em um rato no Hospital Estadual de Rockland, de Nova York (EUA). Nesse artigo, a dupla descreve um "homem ampliado" com alterações de suas funções corporais para melhor se adaptar a viagens espaciais. 
De modo híbrido, o termo ciborgue vem da junção da palavra cybernetic organism e, também, foi utilizado por Clynes na introdução do livro de Halacy (1965), Cyborg: evolution of the superman, na qual discorre sobre uma "nova fronteira" para o ser humano. Isso projeta um exercício flexível de deslocamento cuja transversalidade opera na lógica da completude entre corpo e máquina (e/ou vice-versa).

Ciborgue trata-se, assim, de "um organismo cibernético, um híbrido de máquina e organismo, uma criatura de realidade social e também uma criatura de ficção" (HARAWAY, 2013, p. 36). Nesse contexto, a ideia de ficção possui diversos tipos e estilos de ciborgues e a medicina, também, "uma junção entre organismo e máquina, cada qual concebido como dispositivo codificado, em uma intimidade e com um poder que nunca, antes, existiu" (HARAWAY, 2013, p. 36).

Uma das primeiras tentativas de produzir um ser artificial são os autônomos, criados a partir de material orgânico ou mecânico, animados por eletricidade ou por mecanismo de corda. Para além do lugar comum, o autômato é um ser mecânico capaz de gerar seu próprio movimento (do grego, "agindo pela própria vontade"), que foi inicialmente projetado para brinquedos a partir do conceito de maquinarias de relógios, com experiências que datam desde a antiguidade. $O$ autômato se popularizou, havendo várias formas de produzi-lo, além de exemplos de sua origem está presente em mitos e lendas.

Uma história dos autômatos no Ocidente de divide em quatro estágios: a era mítica, golêmica²; (NAZARIO; NASCIMENTO, 2004), a era dos relógios (séculos XVII e XVIII); a era da máquina a vapor (fim do século XVIII e século XIX); por fim, a era da comunicação e do controle, uma era marcada pela mudança da engenharia de forças para a engenharia da comunicação, ou seja, uma economia da energia para uma economia baseada na reprodução acurada de sinais. (SANTAELLA, 2013, p. 182).

\footnotetext{
${ }^{2}$ Associada a Golem, figura mítica de tradição judaica, um ser artificial trazido à vida por meio da magia.
} 
Conforme a autora, cada estágio representa um tipo de modelagem do corpo humano: como figura de barro, mecanismo de relojoaria, motor aquecido ou informação, próximo de um sistema eletrônico e algoritmo. São tipologias que equacionam a vida alterada pela dinâmica artificial.

$\mathrm{Na}$ Renascença, os autômatos popularizam-se para as mais diversas tarefas e formatos, sendo guardados como tesouros nas cortes reais da Europa. Alguns autômatos eram apenas um modo de ilustrar o organismo humano ou animal. Muitos tinham a habilidade de mover braços, escrever cartas, girar a cabeça e se erguer, ou simplesmente marcar as horas, como em relógios cucos. Em 1774, segundo Rosheim (1994), o relojoeiro suíço Pierre Jaquet-Droz criou um menino autônomo, sentado em uma mesa, capaz de escrever 40 cartas diferentes. No filme de Martin Scorsese, A invenção de Hugo Cabret (2011), baseado em livro de Brian Selznick, um garoto vive solitário em uma estação de trem em Paris tentando reconstruir um autômato. O garoto pegava engrenagens em uma loja de brinquedos para reconstruir seu boneco com o intuito de saber se seu avô havia deixado alguma carta programada em suas funções. Quando o autômato começa a funcionar, ao invés de uma carta, desenha uma cena do filme Viagem à Lua, de Georges Méliès, criado em 1902, para decepção do garoto, que a muito custo tentou reviver o autômato. Na França do século XVII, conforme Wood (2001), os brinquedos mecânicos viraram protótipos para as máquinas da revolução industrial e, depois, as máquinas de guerra. Ou seja, os autômatos foram objetos de mágicos e ilusionistas, instigando as pessoas com suas inúmeras possibilidades:

A construção de autômatos foi uma fase imaginativa e imitativa do percurso técnico, estimulada por uma atitude utilitária, mas que gerou objetos incomuns e de forte apelo estético. Ainda não eram máquinas que direcionavam a eficiência das pessoas no trabalho, mas mexiam com suas concepções e sensibilidade. (CASTRO, 2014, p. 99). 
O autômato popularizou-se cada vez mais no imaginário coletivo e chegou à fiç̧ão científica como robôs com vida própria, desenvolvendo até os atuais ciborgues ou os chamados homens cibernéticos. O humano é fascinado pela sofisticação da experiência artificial.

$\mathrm{Na}$ literatura do século XIX, os autômatos pareciam seres abomináveis que traziam desgraça para seus criadores. Em Autômatos, de 1814, e O homem de areia, de 1816, ambos de E. T. A. Hoffmann, e The bell-tower, de 1885, de Herman Melville, figuravam conotações negativas para a criação da vida artificial. Em O homem de areia, segundo Heise (2006), Hoffmann chega a chamar de maldito autômato a boneca Olímpia, por quem a personagem Natanael se apaixona perdidamente.

Embora ainda seja considerado e reconhecido como clássico do terror contemporâneo, o romance Frankenstein ou o Prometeu moderno, de 1818, de Mary Shelley (2015), trata de uma metáfora relevante da vida artificial no Ocidente. O livro ficou pronto em 1817, mas foi publicado no ano seguinte. Virou um best-seller de imediato, assustando os/as leitores/as e também os editores da época, não acostumados com um livro escrito com tanto vigor por uma jovem de 19 anos.

Mary teve influências de seus pais (os escritores Mary e Willian Godwin) e do marido Percy Shelley (poeta romântico inglês); e vivia cercada de intelectuais, poetas e escritores, como Lord Byron. Porém, foi nas experiências de Luigi de Galvani que serviu de referência para se obter a criatura. Galvani, com testes de correntes elétricas, conseguiu, em 1771, contrair involuntariamente as pernas de uma rã, propondo o uso da eletricidade para reanimar o inanimado. Aproveitando-se dessa descoberta científica, Mary escreveu sobre um jovem chamado Victor Frankenstein fascinado pela capacidade de animação da vida por meio do galvanismo e da eletricidade.

Ao entrar na faculdade, o personagem Victor passa a viver em função de seu projeto: dar vida a partir da morte. O necrotério e o matadouro eram suas fontes de experiência. Nas madrugadas, recolhia restos de cadáveres 
humanos e de animais esquartejados e, aos poucos, ele foi formando um ser híbrido. Utilizando o experimento de Galvani, Victor levou o monstro à vida. Numa primeira impressão, o achava feio, mas a criatura demonstrouse dócil e culta, e até pede para conseguir-Ihe uma noiva. Contrariado e desprezado, o monstro fica incontrolável e busca a destruição de seu criador e da humanidade. Mary conta essa história de várias maneiras, confrontando as visões de Victor sobre o monstro, do monstro sobre as pessoas e de várias pessoas que viram o monstro em sua busca pela aceitação na sociedade.

O subtítulo do romance de Shelley, O Prometeu moderno, remete a duas versões para a história de Prometeu e a autora utilizou as duas. A primeira vem da mitologia grega, de um Titã rebelde que roubou o fogo do Olimpo para socorrer e salvar a humanidade. Isso provocou a ira de Júpiter, rei dos deuses e dos homens, "que mandou acorrentá-lo num rochedo onde um abutre Ihe arrancava o fígado, que se renovava à medida que era devorado" (BULFINCH, 2002, p. 26).

A segunda versão é do escritor romano Ovídio, em Metamorfoses (ano 8 d. C. ), que apresenta Prometeu como criador e manipulador da vida por intermédio de uma porção de iodo. Mary Shelley (2015) usou um pouco de cada versão na criação do monstro por meio do fogo celestial oriundo do uso da eletricidade galvânica. Como a atenção concentra-se no monstro, Victor coloca-se como personagem em segundo plano, mas não para a autora, pois seria esse novo Prometeu, e não a criatura:

No entanto, reconhecemos que é verdade que, no decorrer da narrativa e quanto mais nos aproximamos do final do romance, os dois, Victor e criatura, tenderão a confundirem-se e a fundirem-se e cada um deles terá como objetivo último e última razão de vida (e de morte) a destruição do outro. Finalmente, o fato de a criatura, originalmente sem nome, acabar por ter recebido o nome do seu criador deveria também lembrar-nos que recentrar as nossas reflexões no criador e não na criatura, não só faz sentido como respeita o título do próprio romance. (ARAÚJO; GUIMARÃES, 2015, p. 4-5). 
Victor criou a criatura e, ao abandoná-la, transforma-a em monstro. Posteriormente, o personagem é castigado por suas ações, que levam à sua própria morte pela criatura, à morte de sua noiva e de outras pessoas inocentes. Vale lembrar que o mito de Prometeu trata da transgressão e, ao mesmo tempo, da força da humanidade. Essa dualidade, segundo Araújo e Guimarães (2015), é colocada em dúvida ao longo do texto de Shelley, tanto um transgressor como benfeitor (a) que entrega o fogo para a vida (a imortalidade), fazendo parte da personalidade de Victor.

O monstro tinha olhos grandes e esbugalhados, pele amarela, cabelos negros e dentes brancos. Apesar disso, Victor Frankenstein chamava a criatura de monstro miserável e demoníaco: "Nenhum mortal poderia suportar o horror daquele rosto. Uma múmia a que se desenvolvesse a vida não seria tão horrenda quanto aquele ser miserável. Eu o contemplara antes de concluí-lo; já era feio" (SHELLEY, 2015, p. 133).

O filme de 1931, dirigido por James Whale, popularizou a criatura sem nome como Frankenstein e sua aparência como horrenda e desajeitada, na construção do imaginário popular, inclusive por the criar feições e comportamento de um ser incontrolável e inconsequente. A adaptação é influenciada nitidamente pelo expressionismo alemão, que segundo Silva (2006) foi um movimento cultural que se iniciou nas artes e estendeu-se para o cinema no início da década de 1920. Caracterizou-se pela distorção de cenário e personagens e o uso de luzes em fundos escuros com o objetivo de expressar a maneira como os realizadores viam o mundo, com cenários distorcidos, raios de luz contrastando com as sombras e a presença assustadora da criatura interpretada por Boris Karloff.

\section{A ficção científica}

A ficção científica surge no século XIX, a partir do imaginário tecnocientífico e das mudanças promovidas pela Revolução Industrial. Posteriormente, conforme Regis (2005), obteve força com o avanço da ciência e da tecnologia e com as decorrentes dúvidas em relação a seu 
impacto na sociedade. Embora presente em histórias em quadrinhos, cinema e teatro, entre outros, o gênero consolidou-se na literatura como oposição à ficção praticada à época.

Em 1896, Frank A. Munsey criou um novo formato de revista, impressa em papel barato e com livre acesso às classes populares na Inglaterra e nos Estados Unidos, que misturava ficção com notícias e poesia: as pulp magazines. Em 1926, a ficção científica ganha sua própria revista, a Amazing Stories, com viagens à Lua, terras fantásticas, vida no futuro, energia atômica, mutações e supersseres. Conforme Regis (2012), classificada como scientifiction, a publicação combinava fato científico com fantasia e, na década de 1930 e 1940, a fiç̧ão científica alcançou crescimento como gênero literário popular, envolvendo escritores (as), editores (as) e leitores (as) que produziam e consumiam os títulos que surgiam. Ainda segundo Regis (2012), o termo science fiction surge, em 1929, na revista Science Wonder Stories como subgênero para histórias fantásticas que despertavam o interesse dos leitores (as).

O gênero toma impulso na década de 1940, com uma geração de autores da ficção científica clássica americana, como Isaac Asimov, Robert Heinlein, Theodore Sturgeon, van Vogt, Arthur C. Clarke, James Blish, Ray Bradbury e Alfred Bester, trazidos inicialmente pelas mãos de John W. Campbell Jr. e de outros editores. Essas histórias tratavam de planetas exóticos, aventuras intergalácticas, alienígenas, máquinas inteligentes e robôs, ao abordar questões da atualidade. Um fato decisivo para a credibilidade da fiç̧ão científica, conforme Isaac Asimov (1984), foi a explosão da bomba atômica em agosto de 1945, no Japão. O tema recorrente nas revistas provoca choque no avanço da ciência e propiciando credibilidade acadêmica ao gênero de ficção científica, que discutia o futuro da humanidade e as consequências do avanço científico para o planeta.

Logo, a ficção científica (re)configura mudanças na sociedade, como superpopulação, crise ambiental entre outros, acompanhando as transformações científicas e deixando de lado as fábulas e fantasias. Arthur 
C. Clarke, no romance Náufragos em Selen, de 1961, utilizou os conhecimentos da época para uma viagem à Lua e Isaac Asimov (1984), por sua vez, empregou inovações em seus textos, recebendo elogios de cientistas célebres até os dias de hoje, como o astrônomo Carl Sagan da série de TV americana Cosmos, popular nos anos 1980.

As possibilidades da ficção científica, segundo Pohl (1997), são ampliadas nos anos 1970, trazendo mudanças na forma de abordagem dos temas e adotando uma classificação denominada hard e soft. A hard utiliza temas do campo das ciências teórico-experimentais, enquanto a soft explora temas das ciências humanas. Pohl (1997, p. 7) oferece um sentido mais amplo, em que "ficção científica é uma literatura de mudança": posiciona-se no futuro da raça humana, trazendo origens distintas, extraterrestres e mundos alterados no espaço-tempo, tendo como base a partir do que fazemos no presente.

Para Asimov (1994), o impulso para a fiç̧ão científica, no início do século XX, foram a novas produções de Frankenstein de Mary Shelley que influenciaram uma geração de histórias de robôs devido ao fascínio da tentativa de criar a vida:

\begin{abstract}
Este se revelou um tema central nas histórias de ficção científica que apareceram depois de Frankenstein. A criação de robôs foi considerada como um exemplo típico da arrogância da humanidade, de sua tentativa de usurpar, através da ciência mal aplicada, as prerrogativas divinas. A criação da vida humana, com uma alma, estava reservada apenas para Deus. A tentativa de imitá-lo só poderia produzir uma cópia grosseira, que inevitavelmente se tornaria tão perigosa quanto o Golem e o Monstro. A construção de um robô conduzia, portanto, ao desastre, e a máxima "existem coisas que a humanidade não deve conhecer" foi apregoada vezes sem conta. (ASIMOV, 1994, p. 15).
\end{abstract}

Isaac Asimov (1994), ao publicar mais de quinhentas obras sobre ficção científica, questiona a tradição de robôs que se revoltam contra seus criadores e propõe um estabelecimento criterioso de segurança que, mesmo que venham a falhar, possam ser aperfeiçoados nos modelos seguintes. Esses dispositivos aparecem na Astounding Science Fiction (1942) como as 
Três Regras Fundamentais da Robótica, que mais tarde ficaram conhecidas como Três Leis da Robótica de Asimov. Elas são as seguintes:

1. Um robô não pode fazer mal a um ser humano ou, por omissão, permitir que um ser humano sofra algum tipo de mal.

2. Um robô deve obedecer às ordens dos seres humanos, a não ser que entrem em conflito com a Primeira Lei.

3. Um robô deve proteger a própria existência, a não ser que essa proteção entre em conflito com a Primeira ou a Segunda Lei. (ASIMOV, 1994, p. 18)

Essas leis vão nortear o trabalho de Asimov e influenciar autores contemporâneos que o sucederam. Asimov (2014) apoia-se nessas leis em sua primeira história sobre robôs, Robbie, de 1939, que seria publicada no livro de contos Eu, robô, de 1950. Tal obra literária reúne nove contos publicados (num período de 10 anos), em revistas de ficção científica, relacionados às Três Leis da Robótica. Nos primeiros contos, Robbie, Brincadeira de pegar, Razão e Pegar o coelho, os robôs executam tarefas domésticas, até mesmo em uma estação espacial, colocando à prova as tais leis. Nos contos seguintes (Mentiroso! Pobre robô perdido, Fuga, Prova), novos robôs produzidos pela empresa U.S. Robôs e Homens Mecânicos causam problemas na sociedade por infligirem uma das leis, já que são capazes de ler pensamentos. Começam a mudar a vida social, econômica e política da Terra, misturando-se com os humanos e os confundindo. No último conto, Conflito evitável, as máquinas passam a governar o planeta e têm que enfrentar os grupos antimáquinas.

\footnotetext{
A dependência excessiva dos humanos pelas máquinas tornou-as um marco da ficção científica na mídia impressa, novelas e no cinema. Na década de 1930, a cultura popular apropriou-se do termo robô para identificar as máquinas pensantes que substituem os humanos em todas as suas atividades. O computador, fictício na época, tornou-se cérebro desses seres, comumente tidos como homens mecânicos feitos de metal. Os computadores e os robôs são figurantes antigos do nosso imaginário e de Isaac Asimov, que escreveu inúmeros contos sobre eles, destaque para "I, Robot" publicado em 1950, nos quais apresentou as lendárias leis da robótica. (CHAVES, 2018, p. 118).
} 
De acordo com a citação, a desconfiança da máquina inteligente, que pode revoltar-se contra a humanidade, persiste, mesmo havendo como sensor as Três Leis da Robótica. Em outro livro de Asimov, O homem bicentenário (1976), um robô sofre na busca da humanização. Um androide doméstico, Andrew, desenvolve habilidades (inteligência, criatividade e emoções) provocadas por alguma falha em sua produção ou inovação de seus mecanismos cibernéticos. Andrew quer ser humano e mortal, depois de se apaixonar por uma mulher da família e vê-la envelhecer e morrer. A busca por se tornar humano e encontrar sua natureza como sujeito faz Andrew vestir roupas e procurar uma clínica (oficina), onde realiza o sonho da mortalidade. Evidente que isso desafia o futuro dos robôs e a ameaça das Três Leis da Robótica.

Por certo, Asimov (1994, p. 25) descreve o homem bicentenário como o "desejo de um robô de transformar-se em um ser humano e da forma como realiza aos poucos esse desejo". Nesse universo ficcional de Asimov, o ciborgue emerge como alteração recorrente do cotidiano. Diante da busca pela atualização de dados com inovação e criatividade, tal alteração possibilita a intensidade da experiência contemporânea. Ou seja, seria repensar o modo de expressão da condição humana e sua imortalidade, pois já não seria possível considerar em uma vida natural pautada exclusivamente pela natureza.

\section{0 grão em Black Mirror}

Entre androides, robótica e ciborgue, as novidades da cultura digital propiciam um debate crítico-reflexivo sobre produtos culturais contemporâneos que (re)equacionam algoritmo, pixels, big data, internet das coisas, entre outros. Sem dúvida, o hibridismo tecnológico atual explora a extensão representacional das coisas no mundo - entre o humano e o tecnológico.

Por exemplo, Black Mirror é uma série de ficção científica produzida para a TV britânica Channel Four e distribuída pelo provedor global Netflix 
por serviço de streaming (tecnologia que permite envio multimídia pela internet) como entretenimento de eficiente comercialização no mercadomídia, em franca expansão. Caracterizada por apresentar histórias independentes em cada episódio, o produto audiovisual Black Mirror discute as tecnologias emergentes e suas relações sociais em uma perspectiva futurista e distópica com roteiros bem pessimistas sobre o futuro. A distopia acrescenta um vasto campo de (im)possibilidades, pois gera uma abertura nas discussões sobre argumento, roteiro e enredo.

Lançada em 2011, está em sua quarta temporada da série, além do filme Bandersnatch, de 2018. Nele, o/a espectador/a pode interferir na história dentro de algumas opções dadas pelo roteiro. Seria uma espécie de customização em que o/a usuário/a-interator/a escolhe algumas opções, pré-selecionadas.

\begin{abstract}
A história-base de Black Mirror é difícil de ser definida, pois cada episódio é autônomo. Em contrapartida, a sua pensata, ou seja, seu princípio moral - "algo que salta aos olhos quando se examina de perto" - é facilmente detectada, por ser o fio que une todos os episódios. Uma crítica social muitas vezes sarcástica à (des)humanização pela dependência excessiva das tecnologias, ou apenas uma forma de fazer o público entender como suas próprias vidas estão sendo conduzidas? O elo seria: em uma sociedade futurista (ou nem tanto), na qual as tecnologias ocupam um espaço superdimensionado, as pessoas começam a perder o controle sobre suas próprias vidas ao tentar contrariar o Sistema. (AZAMBUJA; PERRI, 2018, p. 48).
\end{abstract}

A série aborda temas contemporâneos como vigilância, internet, clonagem, redes sociais digitais, realidade aumentada, cultura de massa, sociedade do espetáculo, games dentre outros, na cultura digital. A vinheta de abertura de cada episódio apresenta o espelho escuro se quebrando. Já o nome da série, Black Mirror, faz referência ao espelho negro, como a tela de dispositivos móveis, celulares, smartwatch e computadores que vemos um mundo em nossas mãos e ao mesmo tempo nos vemos refletidos neles. Nesse fluxo, Lemos (2018, p. 15) afirma: 
Quebrar um espelho, na tradição popular, é sempre um presságio de coisas ruins. E é isso que Black Mirror destaca nas quatro temporadas: coisas ruins acontecendo tendo por base o uso permanente dessas telas, seja nas relações pessoais e afetivas, seja na escola, no trabalho ou no lazer. Esse sinal de mau agouro pinta um cenário nada promissor, seja para o presente ou para o futuro, próximo ou distante, da atual sociedade informacional.

Conforme Lemos (2018) e Berto (2017), o que faz a série ser inovadora e, ao mesmo tempo, assustadora são as representações espaciais/temporais de presente, passado e futuro, explorando nossa dependência desses espelhos escuros. Isso requer atenção aos desafios da linguagem tecnológica tendo como a metáfora do espelho como reflexo, que deveria cintilar como caleidoscópio. Isto é, há um hermético conjunto de fragmentos visuais, ao alcance da experiência do (a) observador (a).

Dentre os diversos episódios destaca-se o último da primeira temporada, Toda a sua história (2011), a qual apresenta um dispositivo implantado nos olhos, que grava a ação individual chamado Grão. Por meio do dispositivo, é possível gravar e rever quantas vezes quiser, além de armazenar ou descartar os episódios de sua memória (como se fosse um HD virtual). O episódio começa com uma entrevista de emprego, em que o protagonista, o jovem advogado Liam (Toby Kebbell) começa a rever em sua gravação seu desempenho do dia. Liam é casado com Fi (Jodie Whittaker).

Ao sair da entrevista Liam pretende encontrar com os amigos. Durante o jantar ele é inquirido a falar a respeito da entrevista de emprego e demonstra o formato colaborativo como o dispositivo dos olhos pode ser utilizado. O chamado grão conecta-se a TV e o grupo, presente durante o evento, veem sua história com recursos como "repasse e revisão", para acessar o conteúdo gravado. Ao longo da história, verifica-se a utilização do recurso tecnológico de gravar e retroceder memórias e aqueles que não possuem o grão são considerados marginalizados na sociedade. Nesse compartilhamento de experiências tecnológicas, as gravações das experiências podem ser vistas/lidas pelo (a) espectador (a) (e/ou usuário 
(a)-interator (a) na internet), por meio de qualquer dispositivo digital como na exibição de filmagens do dia-a-dia e como prova do que ocorreu com o sujeito. Com isso, esse grão permite a seleção de memórias, salvar e descartar as experiências negativas ou o que se ser esquecer. Conforme Lemos (2018, p. 39):

Duas questões são interessantes aqui: a da memória, cinematográfica, vinculada ao que o corpo capta do mundo pela visão; e a constituição de uma subjetividade híbrida a partir da relação íntima entre corpo, artefato e informação com a figura do ciborgue [...] $O$ episódio aponta para humanos com implantes inorgânicos, microeletrônicos, na cabeça, fazendo alusão diretamente à figura do ciborgue.

A figura do ciborgue é explorada na série como situação do dia-a-dia. Observa-se que muitos possuem o implante até que o armazenamento da memória causa problemas nas relações de um casal. No decorrer do encontro, Liam percebe uma relação bastante intensa entre sua esposa e o anfitrião Jonas (Tom Cullen). Esta situação gera enorme discussão entre o casal e Liam obriga a esposa a retroceder suas memórias até que localiza no dispositivo uma traição com Jonas atestando sua desconfiança. Ou seja, comprovada a traição com o uso do grão, Liam termina seu relacionamento e isso o leva a se libertar do dispositivo para tentar viver sem gravar suas lembranças.

O grão, assim, torna-se uma oportunidade única de guardar a memória como arquivamento artificial de uma biotecnologia, em processo de desenvolvimento, além dos conflitos com seu uso, ao evidenciar a distopia do futuro ciborgue, conforme destaca Ortega (2007). A irregularidade entre a capacidade na lógica da natureza humana e a vida digital provoca reflexões.

Portanto, o corpo ciborgue no episódio Toda sua história, de Black Mirror, evidencia nossa proposta crítico-reflexiva sobre a (re)dimensão do universo ciborgue e as consequências do uso de dispositivos tecnológicos no cotidiano e nas relações pessoais. No filme, o Grão aponta para uma 
memória da era da produção audiovisual (e suas interpelações) presente nas redes sociais. Cada vez mais, o algoritmo determina o cotidiano, ao se destacar com o Bigdata. No dispositivo tecnológico, informações ficam armazenadas e podem ser descartadas direcionando a história do sujeito no mundo.

Na abrangência do que possa ser denominado corpo contemporâneo, os ciborgues povoam nosso imaginário há décadas, tanto na literatura quanto nas produções cinematográficas. Diante de vasta produção cultural contemporânea, a imagem de suas raízes está na tentativa de criar um ser híbrido (partes humanas e não-humanas) com características especiais que ampliem e otimizem as possibilidades do corpo.

Essas produções culturais, para Quintarelli (2019), apontam para discutição acerca da relação com as tecnologias emergentes e faz vislumbrar as possibilidades da contemporaneidade para o futuro (i)material. De fato, a vida artificial parece fascinar o humano, tanto no anseio de poder alcançar a força do criador quanto no medo de ser superado por essa vida no futuro. De certa maneira, tais produções discutem as tecnologias emergentes de forma distópica, mais próxima do presente do que do futuro. Todavia, a ficção científica tem a pretensão de abordar o futuro, mas discute o passado e presente, com base nos referenciais dos (as) autores (as) das produções. O ciborgue pode assustar, porém está presente há tempos no nosso imaginário, ao gerar pistas de como será o futuro e o presente.

\section{Considerações finais}

A (re)dimensão do ciborgue no âmbito dos produtos culturais contemporâneos equivale-se de uma singularidade da produção de efeito. Tal efeito verifica-se na dinâmica estratégica de constantes, as quais são, devidamente, estados provisórios, parciais, inacabados e, ao mesmo tempo, deslizantes no armazenamento da memória, ao longo do episódio exemplificado. A partir da adaptabilidade ciborgue do corpo humano 
potencializado pelo aparato tecnológico (re)equivalem-se os valores, ao deixar escapar o registro de memória que intercepta o artificial cotidiano.

Com isso, alterar a produção de conhecimento e a produção de subjetividade requer (re)considerar as articulações expostas por esse produto audiovisual, uma vez que sua narrativa impacta o público a partir da produção de informações desencontradas pela intensidade da experiência. Da comunicação à cultura (e vice-versa), experimentar a sensibilidade humana com o auxílio de dispositivos impulsiona um viver diferente, capaz de alternar realidade e virtualidade como extensão de um fluxo de atualizações, domínio e/ou controle.

Do ponto de vista da cultura digital, a revolução digital é tão delicada quanto a vida humana na simplicidade do viver, pois a variação de possibilidades oferecidas por esse episódio mostra e, simultaneamente, esconde o que ocorre como proposta ficcional na narrativa. O fio condutor desse produto cultural esbarra nas ponderações do protagonista a partir de sua memória a(du)Iterada. Por isso, pensar sobre a relação humano/máquina seria talvez ampliar, mais profundamente, a percepção sobre as coisas no mundo.

Dos diversos produtos culturais apresentados neste trabalho, a figura do ciborgue tem evidência como ser do futuro e, de certa forma, ameaçador; porque incorpora desafios inusitados de se (re)dimensionar a inscrição do sujeito no mundo. Por certo, o ciborgue expressa determinada síntese da condição humana alteradas por algoritmo, pixels, big data, bem como a revolução da computação quântica. Desde os primeiros autônomos vistos como dispositivos de poder, passando pela literatura, principalmente Frankenstein, por filmes até Black Mirror apresentam um ciborgue ou homem maquinizado com ressalvas. $E$, sem dúvida, tais produções raramente expõem o ciborgue como desenvolvimento benéfico para o humano. 
Para encerrar, a epígrafe de Hayles (1999), no início deste texto, aposta na condição humana abarcada pela cibernética, cujo "ser humano é antes de tudo o ser encarnado" (p. 283). Então, vale a pena arriscar?!

\section{Referências}

A INVENÇÃO de Hugo Cabret. Direção Martin Scorsese. El.: Ben Kingsley, Sacha Baron Cohen, Asa Butterfield, Chloë Grace Moretz, Jude Law. Estados Unidos: 2011. 1 DVD (127 min.), son., color.

ARAÚJO, Alberto Ribeiro; GUIMARÃES, Armando Rui. Victor Frankenstein: um prometeu moderno? In: GUIMARÃES, Armando Rui; ARAÚjo, Alberto Ribeiro; RIBEIRO, José Augusto; ALMEIDA, Rogério de. Olhares sobre Frankenstein: literatura, educação e cinema. São Paulo: Képos, 2015.

ASIMOV, Isaac. Eu, robô. São Paulo: Aleph, 2014.

ASIMOV, Isaac. No mundo da ficção científica. Rio de Janeiro: Francisco Alves, 1984.

ASIMOV, Isaac. The bicentennial man. New York: Ballantine Books, 1976. ASIMOV, Isaac. Visões de robô. Rio de Janeiro: Record, 1994.

AZAMBUJA, Patricia; PERRI, Cecília. Filosofia e distopia seriadas: sobre Black Mirror e suas relações entre humanos e técnicas. Ícone, Sergipe, v. 16, n. 1, 2018, p. 42-67. Disponível em:

https://periodicos.ufpe.br/revistas/icone/article/view/237077/pdf. Acesso em: 7 out. 2019.

BERTO, Matheus. A sociedade e seu reflexo: uma análise do seriado Black Mirror à luz do pensamento McLuhaniano. In: CONGRESSO BRASILEIRO DE COMUNICAÇÃO, 40, 2017, Curitiba, PR. Anais [...]. Curitiba: Intercom, 2017. Disponível em: http://portalintercom.org.br/anais/nacional2017/resumos/R121625-1.pdf. Acesso em: 9 out. 2019.

\section{BULFINCH, Thomas. O livro de ouro da mitologia (a idade da fábula):}

histórias de deuses e heróis. Rio de janeiro: Ediouro, 2002.

CASTRO, Angélica. Autômatos: a mecânica como imitação da vida. In: CHAUD, E.; SANT'ANNA, T. F. (Org.). In: SEMINÁRIO NACIONAL DE PESQUISA EM ARTE E CULTURA VISUAL, 7, 2014, Goiânia. Anais [...]. Goiânia: UFG-FAV, 2014.

CHAVES, Viviane. Cibernética e ficção científica: uma proposta pedagógica.

Bolema, Rio Claro, v. 32, n. 60, p. 117-133, 2018. Disponível em: http://www.scielo.br/pdf/bolema/v32n60/0103-636X-bolema-32-60-0117.pdf. Acesso em: 5 out. 2019.

HALACY, D. S. Cyborg: evolution of the superman. New York: Harper, 1965. HARAWAY, Donna. Manifesto ciborgue. In: TADEU, Tomaz. (Org.) Antropologia do ciborgue. Belo Horizonte: Autêntica, 2013, p. 33-118.

HAYLES, Nancy Katherine. How we became posthuman: virtual bodies in cybernetics and informatics. Chicago: Chicago University Press, 1999. 
HEISE, Eloá di Pierro. Hoffmann: o irromper do mal. Itinerários, Araraquara, n. 24, p. 163-177, 2006. Disponível em:

https://periodicos.fclar.unesp.br/itinerarios/article/view/2632/2309. Acesso em: 1 abr. 2019.

LEMOS, André. Isso (não) é muito Black Mirror: passado, presente e futuro das tecnologias de comunicação e informação. Salvador: Edufba, 2018.

ORTEGA, Francisco. Corporeidade e biotecnologias: uma crítica fenomenológica da construção do corpo pelo construtivismo e pela tecnomedicina. Ciência \& Saúde Coletiva, Rio de Janeiro, v. 12, p. 381-388, 2007.

POHL, Frederik. The politics of prophecy. In: HASSLER, Donald; WILCOX, Clyde. Politics science fiction. Columbia: University of South Carolina Press, 1997.

QUINTARELLI, Stefano. Instruções para um futuro imaterial. São Paulo: Elefante, 2019.

REGIS, Fatima. Como a ficção científica conquistou a atualidade: tecnologias de informação e mudanças na subjetividade. Intercom, São Paulo, v. XXVIII, n. 2, p. 101-122, jul./dez. 2005.

REGIS, Fatima. Nós ciborgues: tecnologia de informação e subjetividade homem-máquina. Curitiba: Champagnat, 2012.

ROSHEIM, Mark. Robot evolution: the development of anthrobotics. New Jersey: John Wiley \& Sons, 1994.

SANTAELLA, Lucia. Culturas e artes do pós-humano: da cultura das mídias à cibercultura. São Paulo: Paulus, 2003.

SANTAELLA, Lucia. Temas e dilemas do pós-digital. São Paulo: Paulus, 2013. SHELLEY, Mary. Frankenstein ou o Prometeu moderno. São Paulo:

Companhia das Letras, 2015.

SILVA, Michel. O cinema expressionista alemão. Urutágua, Maringá, n. 10, p. 110, 2006. Disponível em: http://www.urutagua.uem.br/010/10silva.pdf. Acesso em: 27 abr. 2017.

TODA a sua história: Black Mirror. Direção Brian Welsh. El.: Tob Kebbell, Jodie Wittaker e Tom Cullen. EUA/Inglaterra, 2011, série de TV, Netflix (44 min.), son., color.

WOOD, Gaby. Edison's eve: a magical history of the quest for mechanical life. New York: Alfred A. Knopf, 2001. 